\title{
Characterization and Lifetime Estimation of High Density Polyethylene Containing a Prodegradant Agent
}

\author{
Cynthia D. C. Erbetta, Raquel C. S. Azevedo, Karen S. Andrade, Maria Elisa S. R. e Silva, \\ Roberto F. S. Freitas, Ricardo G. Sousa*
}

Polymer Science and Technology Laboratory, Chemical Engineering Department, Engineering School, Federal University of Minas Gerais, Belo Horizonte, Brazil

Email: *sousarg@ufmg.br

How to cite this paper: Erbetta, C.D.C., Azevedo, R.C.S., Andrade, K.S., e Silva, M.E.S.R., Freitas, R.F.S. and Sousa, R.G. (2017) Characterization and Lifetime Estimation of High Density Polyethylene Containing a Prodegradant Agent. Materials Sciences and Applications, 8, 979-991. https://doi.org/10.4236/msa.2017.813072

Received: October 31, 2017

Accepted: December 5, 2017

Published: December 8, 2017

Copyright $\odot 2017$ by authors and Scientific Research Publishing Inc. This work is licensed under the Creative Commons Attribution International License (CC BY 4.0).

http://creativecommons.org/licenses/by/4.0/

\begin{abstract}
High density polyethylene (HDPE) samples, containing different concentrations of prodegradant additive $\mathrm{d} 2 \mathrm{w}^{\circledR}$, were prepared. The properties of the samples were evaluated through differential scanning calorimetry (DSC), Fourier transform infrared spectroscopy (FTIR), rheometry, and scanning electron microscopy (SEM). The work contributes to decreasing the products made of non-biodegradable polymeric materials derived from fossil sources which are have become a problem due to their increasingly inappropriate disposal and long degradation time in the environment. The obtained results indicated that there was no degradation of the samples due to processing. No significant changes in melting temperature, crystallinity, viscoelastic behavior, molecular weight and chemical composition were observed. Images from SEM analysis showed particles on HDPE surface, attributed to prodegradant additive $d 2 \mathrm{w}^{\circledR}$. Oxidation Onset Temperature (OOT) results showed that the additive $d 2 w^{\circledR}$ accelerated the degradation of HDPE. The activation energy (Ea) was determined by Ozawa-Wall-Flynn method. The obtained values were used for lifetime estimation of the samples. At $25^{\circ} \mathrm{C}, \mathrm{HDPE}$ with $\mathrm{d} 2 \mathrm{w}^{\circledR}$ showed a lifetime $50 \%$ higher than that of HDPE without this additive. This fact is attributed to the presence of stabilizers in masterbatch $d 2 \mathrm{w}^{\circledR}$ and the absence of oxygen in thermogravimetric analysis.
\end{abstract}

\section{Keywords}

Lifetime, High Density Polyethylene, Prodegradant Agent, Thermogravimetric Analysis, Activation Energy 


\section{Introduction}

Products made of non-biodegradable polymeric materials derived from fossil sources have become a problem due to their increasingly inappropriate disposal and long degradation time in the environment [1]. In Brazil, their consumption increased from $10 \mathrm{~kg}$ to $30 \mathrm{~kg}$ per person-year in a ten-year period. Such increase is due, basically, to the low production cost of these materials, their lightness, high mechanical resistance and ease of fabrication in various shapes, sizes and colors [2]. The widespread use of plastics, particularly polyethylene, has led to the accumulation of plastic waste, which has caused much criticism [3].

Prodegradant additives have been used to reduce the degradation time of plastic bags. One of these additives is $\mathrm{d} 2 \mathrm{w}^{\circledR}$, produced by the British company Symphony and commercialized in Brazil by RES Brasil. They are added as concentrates or masterbatches during polyolefin resins film processing [4]. According to the literature, additive $\mathrm{d} 2 \mathrm{w}^{\circledR}$ is composed by a metal stearate (typically manganese) and stabilizers. The stabilizers are added in order to protect the prodegradant additive during the melting process and to establish the elapsed time before the degradation process starts. The indicated additive concentration ranges from $1 \%$ to $3 \%(\mathrm{w} / \mathrm{w})$ [5] [6].

Some work has been conducted to understand the degradation of polyolefins, and the effect of using degradation-promoting additives in these polymers. However, there remains considerable controversy regarding the degradation of these polymers [4] [5] [7] [8].

According to Santos et al. [9], oxibiodegradable plastics are not supposed to be sent for either composting or anaerobic digestion or to degrade in sanitary landfills. They were designed to degrade and then biodegrade in the presence of oxygen, thus returning to the carbon biological cycle. Their specification assumes their complete digestion by microorganisms, but in a longer period than that required for composting, which is 180 days, and shorter than that of plastic waste disposed in the environment, which is many decades, even centuries.

Chelliah et al. [10] evaluated the effects of the addition of cobalt stearate $(0.25 \%, 0.5 \%, 0.75 \%$ and $1.0 \%)$ in polyethylene terephthalate (PET) on the physical and mechanical properties, and thermo-oxidative degradation of PET based on FTIR and scanning emission microscopy (SEM) analysis, before and after thermal exposure. This study showed that the increased prodegradant additives loading does not contribute much to thermo oxidative degradation.

Thermal stability studies of polymers are of great interest due to their technical and commercial importance, with the kinetic analysis of thermal degradation being a central issue. Through such analyses, it's possible to obtain the activation energy $(E a)$ values, which may be used to estimate the lifetime of the materials. Therefore, they are relevant to indicate the performance of the material while being used [11].

Ea can be determined from non-isothermal thermogravimetric curves at different heating rates. In polymers, this parameter is usually determined by the 
Ozawa-Wall-Flynn method [12] [13]. This method considers that the activation energy of a material, for a given mass loss (conversion), is directly proportional to the $\mathrm{d} \beta / \mathrm{d}(1 / T)$ coefficient, when the inverse of the absolute temperature $(1 / T)$, for a fixed mass loss percentage, is linearly dependent on the log of the heating rate $(\beta)$ used [14]. By this method, the activation energy can be estimated from Equation (1).

$$
E a=-\left(\frac{R}{b}\right) \times \frac{\mathrm{d}(\log \beta)}{\mathrm{d}\left(\frac{1}{T}\right)}
$$

where $E a$ is the estimated activation energy, $R$ is the universal gas constant, $b$ is an iteration variable, $\beta$ is the heating rate and $T$ is the absolute temperature. The Ea estimated is calculated using Equation (1) and a set value of $0.457 / \mathrm{K}$ for b in the first iteration [12] [13].

From this result the lifetime can be estimated, for a constant conversion degree, by using Equation (2).

$$
\log t=\frac{E_{a}}{2.303^{*} R^{*} T f}+\log \left[\frac{E_{a}}{R^{*} \beta}\right]-a
$$

where $t f$ is the lifetime at a certain degradation temperature $(T f)$ and $a$ is a parameter that can be found in tables as a function of the activation energy and temperature $(T f)[15]$.

The Ozawa-Wall-Flynn method is based on the isoconversion method, that is, the reaction mechanism is the same for a given conversion, regardless of the temperature [16].

Although polyethylene has been extensively studied, relatively few reports actually address the investigation of the characterization of this polymer containing a prodegradant agent [17] [18] [19]. Moreover, only Maryudi et al. [19] presented a study related to lifetime estimation of high density polyethylene with a pro-degradant agent. Therefore, the aim of this study was to evaluate and compare some thermal, chemical and rheological properties of HDPE with and without $\mathrm{d} 2 \mathrm{w}^{\circledR}$, as well as estimate their lifetimes by the Ozawa-Wall-Flynn method.

\section{Materials and Methods}

\subsection{Materials}

High density polyethylene (density: $0.957 \mathrm{~g} / \mathrm{cm}^{3}$, MFI: $7 \mathrm{~g} / 10 \mathrm{~min}$ ) was used in granulated form, as supplied by Braskem. Prodegradant additive $\mathrm{d} 2 \mathrm{w}^{\circledR}$ was provided by RES Brasil in masterbatch form with low density polyethylene (LDPE) as a base polymer.

Additive $\mathrm{d} 2 \mathrm{w}^{\circledR}$ was incorporated into HDPE using a Poly Drive mixer from Thermo Haake at $30 \mathrm{rpm}$, at $140^{\circ} \mathrm{C}$, for $5 \mathrm{~min}$. Three mixtures were prepared, by adding $2 \%, 5 \%$ and $10 \%(\mathrm{w} / \mathrm{w})$ of $\mathrm{d} 2 \mathrm{w}^{\circledR}$ to $50 \mathrm{~g}$ of HDPE.

\subsection{Fourier Transform Infrared Spectroscopy (FTIR) Analysis}

FTIR spectra, in the $4000-650 \mathrm{~cm}^{-1}$ range, were obtained with a FTIR spectro- 
meter model Nicolet 6700 from Thermo Fisher SCIENTIFIC, using attenuated total reflection (ATR) mode, with 64 scans and resolution of $4 \mathrm{~cm}^{-1}$ (Ge crystal). This test was performed to identify changes in the chemical composition of samples containing the prodegradant additive.

\subsection{Differential Scanning Calorimetry (DSC) Analysis}

DSC analyses were employed to determine the melting temperature (Tm), crystallinity and oxidation onset temperature (OOT). A Shimadzu apparatus model DSC-60 was used with an aluminum sample holder. The analysis conditions for the determination of Tm and of the degree of crystallinity followed ASTM D3418-12 (Standard Test Method for Transition Temperatures and Enthalpies of Fusion and Crystallization of Polymers by Differential Scanning Calorimetry) [20]. For the OOT test, synthetic air was used as a flow gas and the analysis conditions followed ASTM E2009-08 (Test method C) (Standard Test Method for Oxidation Onset Temperature of Hydrocarbons by Differential Scanning Calorimetry) [21].

\subsection{Rheometry Analysis}

Rheological tests were performed in a rotational rheometer, model AR-G2 (TA Instruments), using plate-plate geometry, at $140^{\circ} \mathrm{C}$ (higher than the HDPE melting temperature). The linear viscoelasticity region was determined from storage $\left(G^{\prime}\right)$ and loss $\left(G^{\prime \prime}\right)$ moduli plots as a function of strain (\%), in a strain sweep test. This test also allowed the identification of the elastic or viscous domain in the rheological behavior of the samples. The frequency sweep test was performed to determine the variation of the weight average molecular weight $(\mathrm{Mw})$ of the samples. The frequency was varied from 0.8 to $400 \mathrm{rad} / \mathrm{s}$, and, as a control variable (\% strain), the value of $2.5 \%$ was used, which is within the linear viscoelasticity region.

\subsection{Thermogravimetric Analysis (TG)}

TG measurements were performed with heating rates of $2^{\circ} \mathrm{C} / \mathrm{min}, 4^{\circ} \mathrm{C} / \mathrm{min}$, $6^{\circ} \mathrm{C} / \mathrm{min}, 8^{\circ} \mathrm{C} / \mathrm{min}$ and $10^{\circ} \mathrm{C} / \mathrm{min}$, in nitrogen atmosphere. A Shimadzu apparatus, model TGA-50, was used. The analysis conditions for the determination of Ea followed ASTM E1641-07 (Standard Test Method for Decomposition Kinetics by Thermogravimetry Using the Ozawa/Flynn/Wall Method) [22] and for lifetime determination followed ASTM E1877-13 (Standard Practice for Calculating Thermal Endurance of Materials from Thermogravimetric Decomposition Data) [15]. A mass loss of $10 \%$ was considered for the calculation of the activation energy.

\subsection{Scanning Electron Microscopy (SEM) Analysis}

A scanning electron microscope model TM3000 tabletop microscope (Hitachi), at a voltage of $15.0 \mathrm{kV}$, was used for the SEM tests, and the obtained images were 
processed using the TM3000 software. All samples were analyzed at room temperature $\left(20^{\circ} \mathrm{C}\right)$. There was no need for sample coating with gold, as this analysis was conducted under low vacuum.

\section{Results and Discussion}

The spectra of all the analyzed samples are presented in Figure 1. The FTIR analysis did not allow the identification of significant spectral changes between the HDPE samples with and without additive. All the bands identified in the spectra are characteristic of polyethylene, that is, stretching between $2950 \mathrm{~cm}^{-1}$ and $2850 \mathrm{~cm}^{-1}$, bending between $1470 \mathrm{~cm}^{-1}$ and $1350 \mathrm{~cm}^{-1}$ and rocking close to $700 \mathrm{~cm}^{-1}$ [23]. None of the analyzed spectra presented band close to $1700 \mathrm{~cm}^{-1}$, assigned to carbonyl group $(\mathrm{C}=\mathrm{O})$ [24], suggesting that there was no HDPE degradation during processing.

Figure 2 shows the second-run DSC curves of HDPE, $\mathrm{d} 2 \mathrm{w}^{\circledR}$ and HDPE with $2 \%, 5 \%$ and $10 \% \mathrm{~d} 2 \mathrm{w}^{\circledR}$ samples. An endothermic event (melting) of similar profile was observed for HDPE samples with and without additive, contrasting to that of the $\mathrm{d} 2 \mathrm{w}^{\circledR}$ sample.

Table 1 summarizes DSC obtained data of the analyzed samples. Crystallinity was calculated using Equation (3) [25].

$$
\text { Crystallinity }(\%)=\left(\frac{\Delta H m}{\Delta H m^{c}}\right) \times 100
$$

where $\Delta \mathrm{Hm}^{c}$ is the melting enthalpy of $100 \%$ crystalline $\operatorname{HDPE}(289 \mathrm{~J} / \mathrm{g})$ and $\triangle H m$ is the melting enthalpy of the sample.

DSC results presented in Table 1 show greater thermo-oxidative stability for

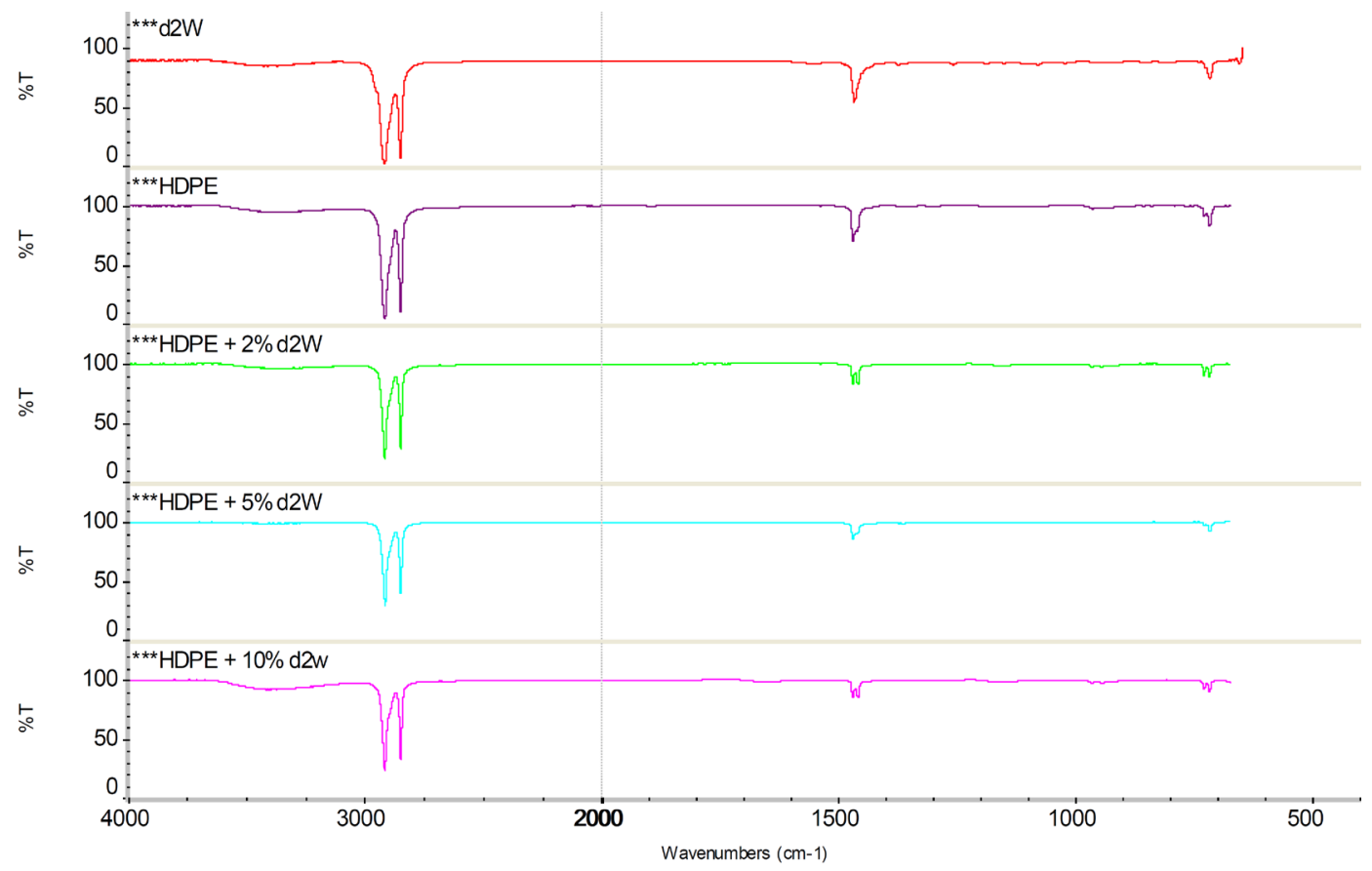

Figure 1. FTIR spectra for HDPE, $\mathrm{d} 2 \mathrm{w}^{\circledR}$ and HDPE with $2 \%, 5 \%$ and $10 \% \mathrm{~d} 2 \mathrm{w}^{\circledR}$ samples. 


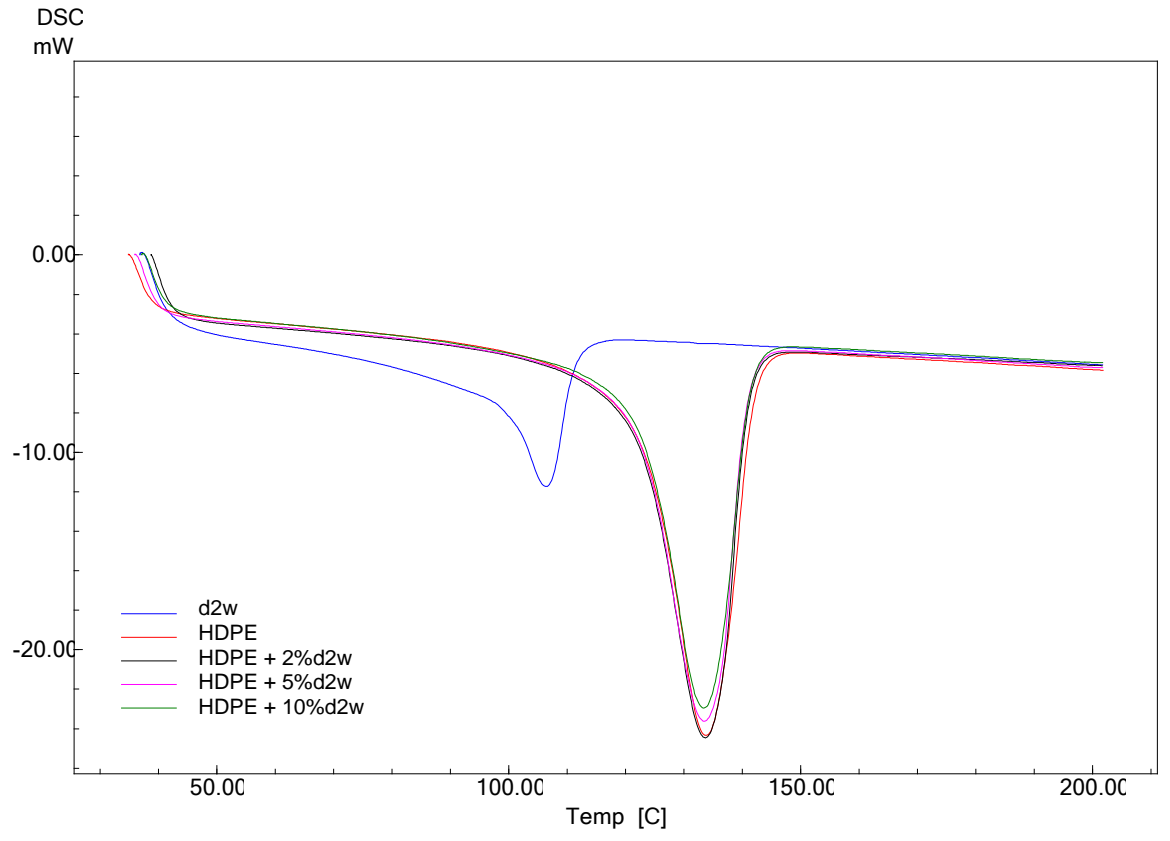

Figure 2. DSC curves for HDPE, $\mathrm{d} 2 \mathrm{w}^{\circledR}$ and HDPE with $2 \%, 5 \%$ and $10 \% \mathrm{~d} 2 \mathrm{w}^{\circledR}$ samples.

Table 1. DSC results.

\begin{tabular}{ccccc}
\hline \multirow{2}{*}{ SAMPLE } & \multicolumn{5}{c}{ DSC } \\
\cline { 2 - 5 } & $\mathrm{T}_{\mathrm{m}}\left({ }^{\circ} \mathrm{C}\right)$ & $\Delta \mathrm{H}_{\mathrm{m}}(\mathrm{J} / \mathrm{g})$ & Crystallinity (\%) & OOT $\left({ }^{\circ} \mathrm{C}\right)$ \\
\hline $\mathrm{HDPE}$ & 134 & 178 & 62 & 230 \\
$\mathrm{~d}_{2} \mathrm{w}^{\circledR}$ & 106 & 82 & 28 & 241 \\
$\mathrm{HDPE}+2 \% \mathrm{~d}_{2} \mathrm{w}^{\circledR}$ & 134 & 181 & 62 & 217 \\
$\mathrm{HDPE}+5 \% \mathrm{~d}_{2} \mathrm{w}^{\circledR}$ & 133 & 177 & 61 & 222 \\
$\mathrm{HDPE}+10 \% \mathrm{~d}_{2} \mathrm{w}^{\circledR}$ & 133 & 169 & 59 & 222 \\
\hline
\end{tabular}

the $\mathrm{d} 2 \mathrm{w}^{\circledR}$ sample (highest OOT), which is attributed to the presence of stabilizers in the masterbatch. The OOT values of the samples of HDPE with $d 2 \mathrm{w}^{\circledR}$ are $8^{\circ} \mathrm{C}$ to $13^{\circ} \mathrm{C}$ lower than that of HDPE without additive.

The crystallinity and melting temperature of all samples were determined after removing their thermal history (second-run tests). It's observed that the melting temperature and the crystallinity of the $\mathrm{d} 2 \mathrm{w}^{\circledR}$ sample are lower than those of the other samples. Such result can be understood as far as the masterbatch base polymer is LDPE. It's also observed that the crystallinity and the melting temperature of the HDPE with additive samples, in all concentrations, are, basically, the same of the HDPE without additive sample, due, certainly, to the small amount of $d 2 w^{\circledR}$ added.

Through the strain sweep test, the linear viscoelasticity region could be determined as being between $0.1 \%$ and $10 \%$ of strain. The strain value chosen for the frequency sweep test was $2.5 \%$. The obtained results from the frequency sweep test, for HDPE, $d 2 w^{\circledR}$ and HDPE with $2 \% d 2 w^{\circledR}$ are presented in Figure 3. In this figure, the storage or elastic modulus ( $\mathrm{G}^{\prime}$, in red) and the loss or viscous 
modulus (G”, in blue) are shown as functions of angular frequency. The curves (G'or G" versus angular frequency), obtained for the HDPE with 5\% and 10\% $\mathrm{d} 2 \mathrm{w}^{\circledR}$ samples, are similar to those presented in Figure 3.

From the rheological tests, at $140^{\circ} \mathrm{C}$, it was observed that, for all samples, the viscous effect predominated over the elastic effect $\left(G^{\prime \prime}>G^{\prime}\right)$. These results suggest that the rheological behavior of HDPE was preserved in the additivated samples. The results, for the weight average molecular weight $(\mathrm{Mw})$ of HDPE and HDPE with $2 \%, 5 \%$ and $10 \% \mathrm{~d} 2 \mathrm{w}^{\circledR}$ samples, obtained from the frequency sweep tests (relative results, just for comparison purposes), are presented in $\mathrm{Ta}$ ble 2. It can be observed that the values of $\mathrm{Mw}$ are in the same order of magnitude $(105 \mathrm{~g} / \mathrm{mol})$, with no significant change.

SEM images of all samples are shown in Figure 4. The micrograph of HDPE is shown in Figure 4(a). It can be noted that the surface presents integrity and a non-porous appearance. In Figure 4(b), it's shown the micrograph obtained for the prodegradant additive $d 2 \mathrm{w}^{\circledR}$, where it can be observed clusters in the surface. The micrographs shown in Figures 4(c)-(e) are for the samples of HDPE with $2 \%, 5 \%$ and $10 \% \mathrm{~d} 2 \mathrm{w}^{\circledR}$, respectively. It's possible to observe that the aspect of the samples is similar (integral and non-porous), but small particles can be seen in the surface, related to the presence of $d 2 \mathrm{w}^{\circledR}$. Also, the number of particles increases as $d 2 w^{\circledR}$ concentration increases.

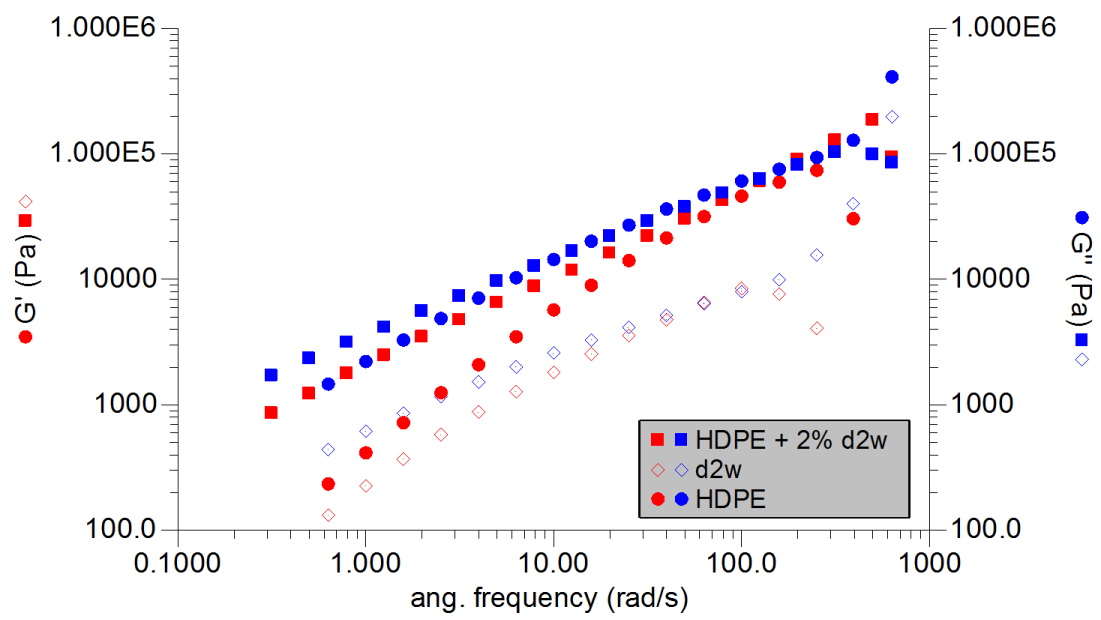

Figure 3. Curves from frequency sweep test for HDPE, $d 2 w^{\circledR}$ and HDPE with $2 \% d 2 w^{\circledR}$ samples.

Table 2. Results for the weight average molecular weight $(\mathrm{Mw})$, from the frequency sweep test.

\begin{tabular}{cc}
\hline SAMPLE & Mw (g/mol) \\
\hline HDPE & $6.4 \times 10^{5}$ \\
HDPE $+2 \% \mathrm{~d}_{2} \mathrm{w}^{\circledR}$ & $6.9 \times 10^{5}$ \\
$\mathrm{HDPE}+5 \% \mathrm{~d}_{2} \mathrm{w}^{\circledR}$ & $6.1 \times 10^{5}$ \\
$\mathrm{HDPE}+10 \% \mathrm{~d}_{2} \mathrm{w}^{\circledR}$ & $6.4 \times 10^{5}$
\end{tabular}



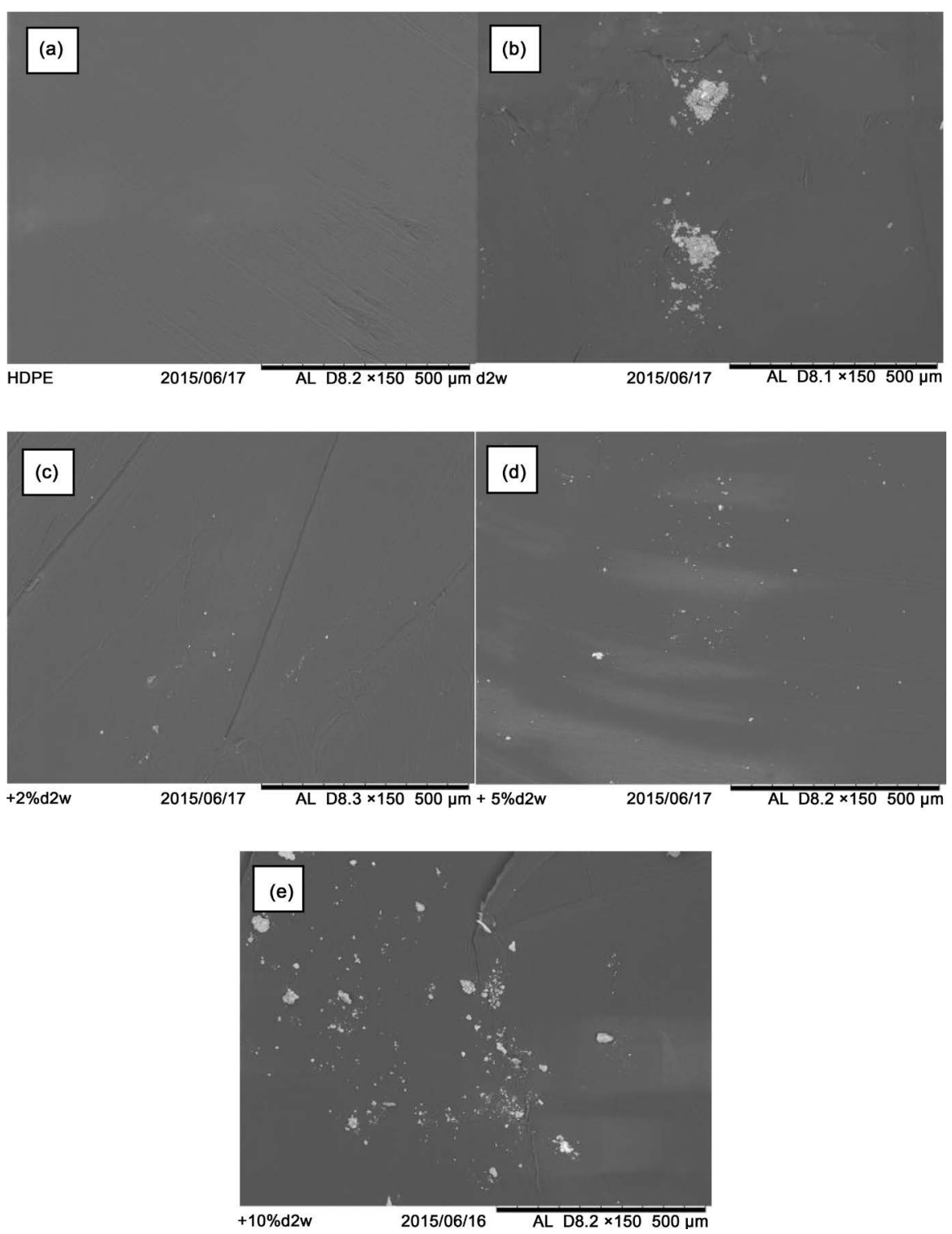

Figure 4. Micrographs for HDPE (a), additive $\mathrm{d} 2 \mathrm{w}^{\circledR}$ (b) and HDPE with $2 \%$ (c), 5\% (d) and $10 \%(\mathrm{e})$ additive $\mathrm{d} 2 \mathrm{w}^{\circledR}$ samples.

For the study of the lifetime of additivated HDPE, the sample with $2 \% \mathrm{~d} 2 \mathrm{w}^{\circledR}$ was chosen, considering the amount normally recommended, by the manufacturer, for commercial use [6]. In Figure 5 and Figure 6, TG curves, at different heating rates, for HDPE and HDPE with $2 \% \mathrm{~d} 2 \mathrm{w}^{\circledR}$, are presented. Both samples exhibited thermal degradation in a single step related to the complete degradation of polymer chains. Since thermal degradation occurred in a single step, at all heating rates, the Ozawa-Wall-Flynn method can be applied, in order to calculate the activation energy. A linear correlation between the logarithm of the conversion rate and the inverse of the absolute temperature, at conversion rates of $5 \%, 10 \%$ and $20 \%$, indicates that the thermal degradation of both pure and additivated HDPE $\left(2 \% \mathrm{~d} 2 \mathrm{w}^{\circledR}\right)$ samples is of a $1^{\text {st }}$ order reaction type.

Equation (1) and the obtained data from the curves shown in Figure 5 and 


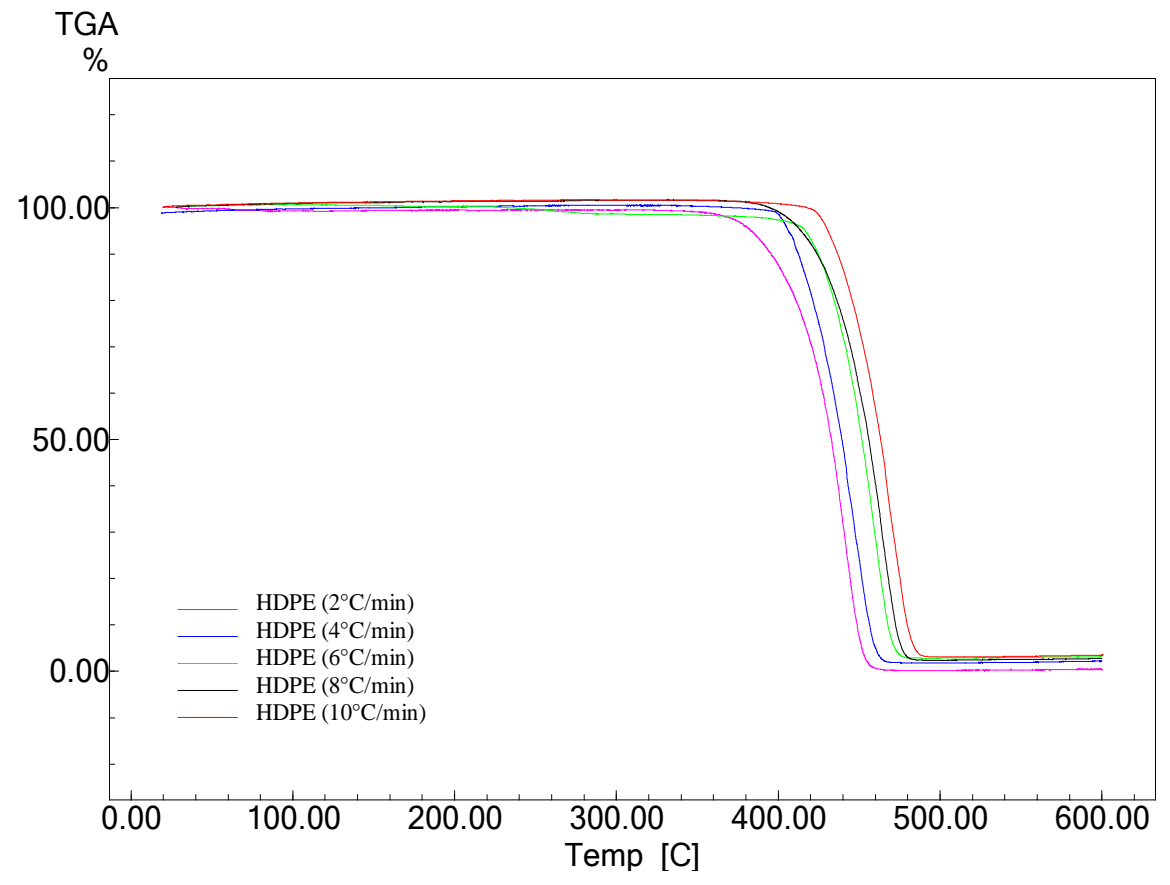

Figure 5. TG curves for HDPE, at different heating rates.

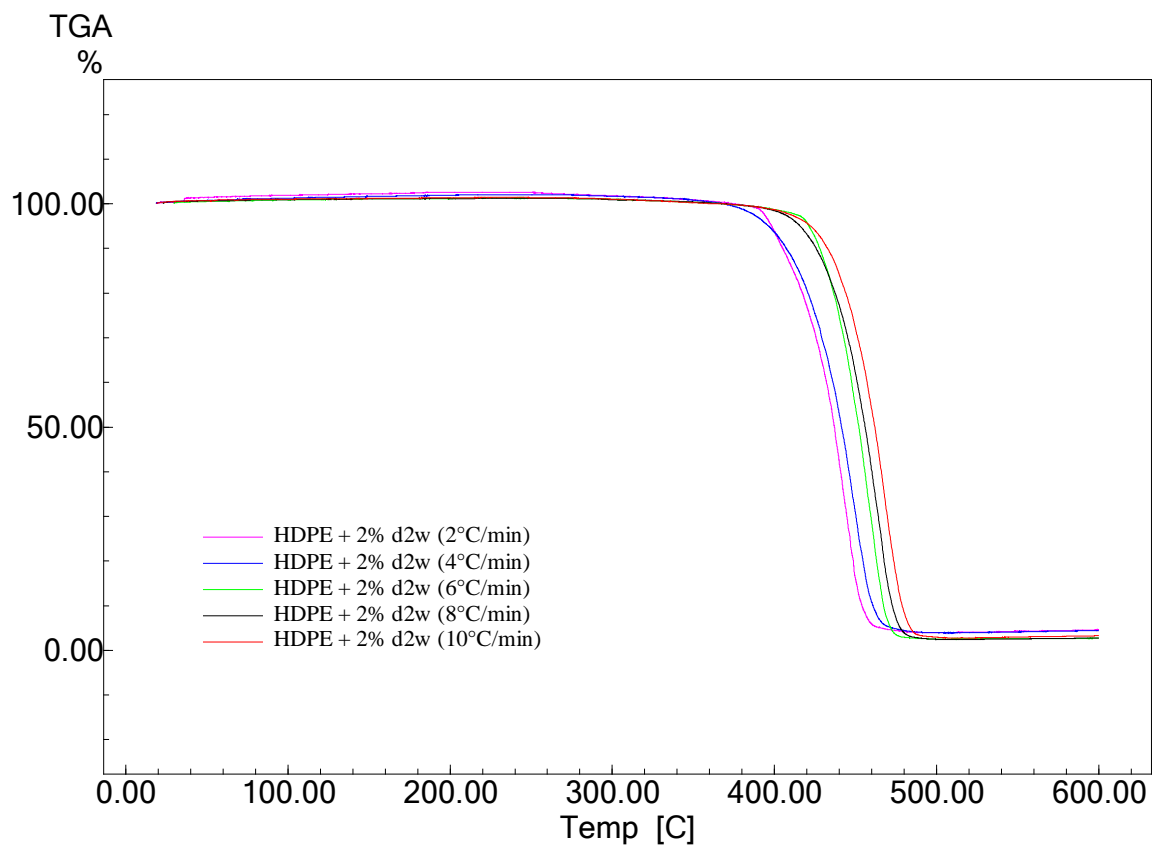

Figure 6. TG curves for HDPE with $2 \% \mathrm{~d} 2 \mathrm{w}^{\circledR}$, at different heating rates.

Figure 6, at $10 \%$ conversion, were used to calculate the activation energy of pure and additivated HDPE $\left(2 \% \mathrm{~d} 2 \mathrm{w}^{\circledR}\right)$ samples. The results are presented in Table 3.

From the results shown in Table 3, a higher value for the activation energy of HDPE additivated sample is observed. It means that it has a greater thermal stability in comparison to the non-additivated HDPE, probably due to the presence of stabilizers in prodegradant agent masterbatch. The opposite behavior was observed in OOT and DSC analyses, where pure HDPE showed greater stability. 
Table 3. Activation Energies for pure and additivated HDPE samples (10\% conversion).

\begin{tabular}{cc}
\hline SAMPLE & $E_{a}(\mathrm{~kJ} / \mathrm{mol})$ \\
\hline HDPE & 225.95 \\
HDPE $+2 \% \mathrm{~d}_{2} \mathrm{w}^{\circledR}$ & 274.78 \\
\hline
\end{tabular}

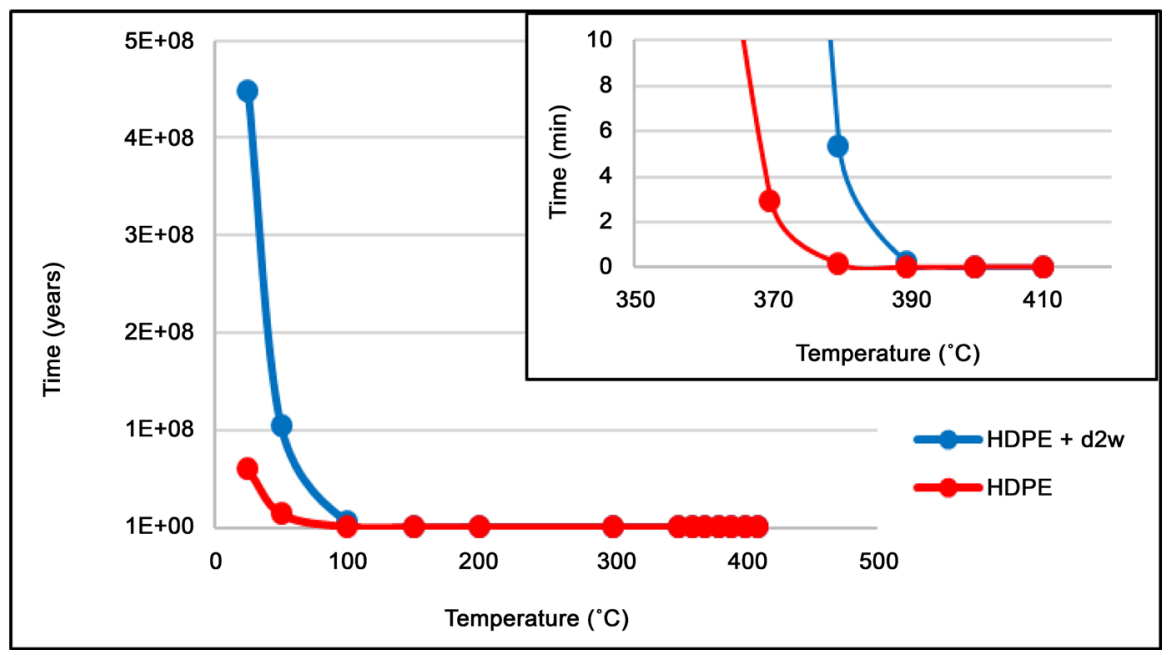

Figure 7. Lifetime versus temperature for HDPE and HDPE $2 \% \mathrm{~d} 2 \mathrm{w}^{\circledR}$ samples.

This fact could be related to the type of atmosphere used in each analysis, nitrogen in TG and synthetic air in DSC. Oxygen may induce degradation reactions of polymer chains, probably catalyzed by $\mathrm{d} 2 \mathrm{w}^{\circledR}$.

A similar behavior was observed for $\mathrm{d} 2 \mathrm{w}^{\circledR}$-additivated polypropylene in a study by Carvalho et al. [17], using OIT (oxidation induction time), MFI (melt flow index), FTIR and mechanical tests and TG techniques to determine Ea.

The estimated lifetime of the polymers was taken as the one in which the mass loss was $10 \%$, at different temperatures, as shown in Figure 7. The lifetime was calculated using Equation (2). From the results shown in this figure, it's observed that the lifetime of both the additivated and non-additivated HDPE is quite high, at $25^{\circ} \mathrm{C}$, with higher values for the additivated HDPE $\left(45 \times 10^{7}\right.$ years $)$ compared to the non-additivated HDPE $\left(6 \times 10^{7}\right.$ years). Therefore, as temperature being the only effect, in an inert atmosphere, and for a prodegradant agent concentration of $2 \%(\mathrm{w} / \mathrm{w})$, the lifetime of HDPE showed an increase of 7.5 times. By zooming the curves of Figure 7 (time in min.), for a better visualization of the correlation between lifetime and temperature of the samples, one obtains the curves in the top right of this Figure. From $390^{\circ} \mathrm{C}$, a similar behavior of the samples was observed, that is, the lifetime of the additivated HDPE sample is the same that of the non-additivated one.

Roy et al. [17] determined the lifetime of LDPE (taken as the time for 5\% mass loss) additivated with cobalt stearate as a prodegradant agent. The additive was directly incorporated into LDPE during extrusion, without a masterbatch, that is, without the influence of the stabilizer load, which are normally used in masterbatches. As a result, the lifetime of additivated LDPE was significantly reduced in 
both an inert and an oxidizing atmosphere. Maryudi et al. [19] evaluated the effect of the addition of $1 \%$ manganese laurate on HDPE. This prodegradant agent was synthesized by the authors and mixed directly to the polymer during extrusion, in a way similar to that used by Roy et al. [18]. They reported an accelerated degradation of the additivated HDPE.

These results corroborate the hypothesis that stabilizers present in the prodegradant agent masterbatch may be responsible for the increased thermal stability of additivated HDPE, when considering only the effect of the temperature under inert atmosphere.

\section{Conclusions}

The results presented in this study indicate that the addition of prodegradant agent $d 2 \mathrm{w}^{\circledR}$ to HDPE practically did not affect polymer properties: melting temperature and crystallinity, viscoelastic behavior, molecular weight and chemical composition.

Considering only the effect of temperature under inert atmosphere, the additivated polymer presented greater thermal stability (higher activation energy values), and, as a consequence, an increased lifetime. This behavior may be related to the presence of stabilizers in the masterbatch additionally to the absence of oxygen in the medium, since additivated samples were less thermally stable in an oxidizing atmosphere, as demonstrated by OOT analysis. In conclusion, the prodegradant agent became effective, that is, it really started its activity, only after the thermal degradation of the polymer had begun, when in the absence of oxygen. In presence of oxygen in the medium, the activation energy values should be much smaller than those found in inert atmosphere. Its efficiency is directly related to the presence of oxygen in the medium. The temperature, alone, does not play a fundamental role in the action of the prodegradant additive evaluated in these studies.

\section{Acknowledgements}

The authors thank the Polymer Engineering Laboratory and CompositesLEPCom UFMG, for the important collaboration in the preparation of the samples, RES Brasil Company for providing the additive, Braskem Company for supplying HDPE samples, CEMIG, PETROBRAS, FAPEMIG, CAPES and CNPq for all financial support for this research.

\section{References}

[1] Brito, G.F., Agrawal, P., Araújo, E.M. and Mélo, T.J.A. (2011) Biopolymers, Biodegradable Polymers and Polymer Green. Revista Eletrônica de Materiais e Processos, 6, 127-139. http://www.dema.ufcg.edu.br/revista/

[2] Santos, P.A, Oliveira, M.N., De Paoli, M.A., Freitas, V.G. and Rosa, D.S. (2013) Pro-Oxidant Effect Evaluation in PP in blends with PHB. Polímeros. Ciência e Tecnologia, 23, 432-439. https://doi.org/10.4322/polimeros.2013.036 
[3] Thompson, R.C., Olsen, Y., Mitchell, R.P., Davis, A., Rowland, S.J., John, A.W.G., McGonigle, D. and Russell, A.E. (2004) Lost at Sea: Where Is All the Plastic? Science, 304, 838-838. https://doi.org/10.1126/science.1094559

[4] Dalmolin, E. (2007) Avaliação de Polietilenos Contendo Aditivos Pró-Degradante. M.Sc. Dissertation, Federal University of Rio Grande do Sul, Porto Alegre.

[5] Ammala, A., Bateman, S., Dean, K., Petinakis, S., Sangwan, P., Wong, S., Yuan, Q. and Yu, L. (2011) An Overview of Degradable and Biodegradable Polyolefins. Progress in Polymer Science, 36, 1015-1049. https://doi.org/10.1016/j.progpolymsci.2010.12.002

[6] Ammala, A., Bateman, S., Dean, K., Petinakis, E., Sangwan, P., Wong, S., Yuan, Q., Yu, L., Patrick, C. and Leong, K.H. (2011) An Overview of Degradable and Biodegradable Polyolefins. Progress in Polymer Science, 36, 1015-1049. https://doi.org/10.1016/j.progpolymsci.2010.12.002

[7] Roy, P.K., Hakkarainen, M., Varma, I.K. and Albertsson, A.C. (2011) Degradable Polyethylene: Fantasy or Reality. Environmental Science \& Technology, 45, 4217-4227. https://doi.org/10.1021/es104042f

[8] Selke, S., Auras, R., Nguyen, T.A., Aguirre, E.C., Cheruvathur, R. and Liu, Y. (2015) Evaluation of Biodegradation-Promoting Additives for Plastics. Environmental Science \& Technology, 49, 3769-3777. http://pubs.acs.org/doi/abs/10.1021/es504258u https://doi.org/10.1021/es504258u

[9] Santos, A.S.F., Freire, F.H.O., Costa, B.L.N. and Manrich, S. (2012) Plastic Bags: Sustainable Destinations and Replacement Alternatives. Polímeros. Ciência e Tecnologia, 22, 228-237. https://doi.org/10.1590/S0104-14282012005000036

[10] Chelliah, A., Subramaniam, M., Gupta, R. and Gupta, A. (2017) Evaluation on the Thermo-Oxidative Degradation of PET Using Prodegradant Additives. Indian Journal of Science and Technology, 10, 1-5.

http://www.indjst.org/index.php/indjst/article/view/1112122 https://doi.org/10.17485/ijst/2017/v10i6/111212

[11] Batista, N.L., Costa, M.L., Iha, K. and Botelho, E.C. (2013) Evaluation of Thermal Degradation and the Estimated Useful Lives of Compounds Poly(ether imide)/Carbon Fiber. Proceedings of the 12 th Brazilian Congress of Polymers (CBPol), Florianópolis, 22-26 September 2013.

[12] Ozawa, T. (1965) New Method of Analyzing Thermogravimetric Data. Bulletin of Chemical Society of Japan, 38, 1881-1886. https://doi.org/10.1246/bcsj.38.1881

[13] Flynn, J.H. and Wall, L.A. (1966) A Quick Direct Method for the Determination of Activation Energy from Thermogravimetric Data. Journal of Polymers Science-Part B: Polymer Letters, 4, 323-328. https://doi.org/10.1002/pol.1966.110040504

[14] Horn, M.M., Martins, V.C.A. and Plepis, A.M.G. (2010) Activation Energy Determination in Polymeric Hydrogels from TGA Data. Polímeros: Ciência e Tecnologia, 20, 201-204. https://doi.org/10.1590/S0104-14282010005000025

[15] ASTM E1877-13. Standard Practice for Calculating Thermal Endurance of Materials from Thermogravimetric Decomposition Data, 2013.

[16] Batista, N.L. (2012) Influence of Weather on the Thermal and Mechanical Properties of Composite PEI/Carbon Fiber. M.Sc. Dissertation, Technological Institute of Aeronautics, São José dos Campos.

[17] Carvalho, C.L., Silveira, A.F. and Rosa, D.S. (2013) A study of the Controlled Degradation of Polypropylene Containing Pro-Oxidant Agents. Springer Plus, 2, 623. https://doi.org/10.1186/2193-1801-2-623 
[18] Roy, P.K, Surekha, P., Rajagopal, C. and Choudhary, V. (2007) Thermal Degradation Studies of LDPE Containing Cobalt Stearate as Pro-Oxidant. eXPRESS Polymer Letters, 1, 208-216. https://doi.org/10.3144/expresspolymlett.2007.32

[19] Maryudi, A.H., Rosli, M.Y. and Mohammad, D.H.B. (2013) Thermo-Oxidative Degradation of High Density Polyethylene Containing Manganese Laurate. International Journal of Engineering Research and Applications (IJERA), 3, 1156-1165. http://www.ijera.com/pages/v3no2.html

[20] ASTM D3418-12e1. (2012) Standard Test Method for Transition Temperatures and Enthalpies of Fusion and Crystallization of Polymers by Differential Scanning Calorimetry.

[21] ASTM E2009-08e1. (2014) Standard Test Methods for Oxidation Onset Temperature of Hydrocarbons by Differential Scanning Calorimetry.

[22] ASTM E1641-07. (2007) Standard Test Method for Decomposition Kinetics by Thermogravimetry.

[23] Snyder, R.G. (1980) Spectroscopic Methods-Methods in Experimental Physics, 16 (A) 73. Academic Press, New York, 73-240.

[24] Hinsken, H., Moss, S., Pauchet, J. and Zweifel, H. (1991) Degradation of Polyolefin during Melt Processing. Polym Degrad Stab, 34, 279-293. https://doi.org/10.1016/0141-3910(91)90123-9

[25] Peacock, A.J. (2000) Handbook of Polyethylene-Structures, Properties and Applications. Marcel Dekker, New York, 123-375. 